\title{
Legal aspect of social entrepreneurship
}

\author{
Uliana Filatova ${ }^{1,2}$, Nina Semeryanova $^{3}$, Svetlana Suslova $^{4}$, Alena Gabudina ${ }^{5}$, Anna \\ Kopytova ${ }^{5, *}$ \\ ${ }^{1}$ Irkutsk State University, Karl Marx str., 1, Irkutsk, 664003, Russia \\ ${ }^{2}$ East Siberian branch Russian state University of justice, Ivana Franko str., 23 -a, Irkutsk, 664074, \\ Russia \\ ${ }^{3}$ South Ural State University (National Research University), Nizhnevartovsk Branch, Mira str., 9, \\ 628600, Russia \\ ${ }^{4}$ Irkutsk Institute (Branch), All-Russian State University of Justice. Nekrasov str., 4, Irkutsk, 664011, \\ Russia \\ ${ }^{5}$ Tyumen Industrial University, Volodarskogo str., 38, Tyumen, 625000, Russia
}

\begin{abstract}
The article discusses the main issues of definition of social entrepreneurship, both from economic and legal point of view. Since Russian legislature is only at the beginning of the way to create legal framework for activities, legislation on social entrepreneurship seems fragmentary and inconsistent. All of that adversely affects development of social entrepreneurship. Official city statistics (Nizhnevartovsk) show that less than a third of all entrepreneurs are interested in this type of activity; entrepreneurs who already have business in the field of social entrepreneurship mostly do not plan to expand current activities in this area. Analysis can contribute to creation of developed socio-economic relations in Russia. It can be achieved by building effective relations between social entrepreneurs and beneficiaries on the one hand, and also between social entrepreneurs and the state on the other.
\end{abstract}

\section{Introduction}

According to Article 6 of the Constitution, the Russian Federation is a social state. Its policy is aimed at creating conditions ensuring decent life and free development of a person. In development of the idea of social state, in the second paragraph of the indicated article there are listed subjects that need special social support from the state: family, mothers, fathers, children, disabled people, and senior citizens. The directions of state activity in this area are designated: labor and health protection, establishment of guaranteed minimum wage, development of system of social services, establishment of state pensions, benefits and other guarantees of social protection.

Social mission of the state is usually associated with activities of the state itself and system of social services created by the state. So, according to the Ministry of Finance of Russian Federation, about $30 \%$ of expenditure part of the budget of Russian Federation consists of social policy directions. However, pronounced tendency of recent years has been active involvement in social sphere of elements of civil society and state's full support

\footnotetext{
*Corresponding author: semeryanova@yandex.ru
} 
for social entrepreneurship. It suggests that in the future many functions of the state in social sphere will be transferred to business entities. In November 2018, Dmitry Sazonov, Deputy Chairman of the State Duma Committee on Economic Policy, Industry, Innovative Development and Entrepreneurship, confirmed the need for a draft law on social entrepreneurship, noted that the Government of Russian Federation would direct efforts to develop this area. He believes that it is necessary to gradually increase the share of presence of non-governmental organizations in social services market, reaching $50 \%$ by 2024 . In addition, it is necessary to create a register of activities that can be offered in the social services market, and also to develop a standard for uniform high quality of their provision. [1]

The "Concept of long-term socio-economic development of Russian Federation for the period up to 2020 " is the document testifying to progressive development of the state in designated direction. The concept establishes the main goal of social state to develop human potential through systemic transformations aimed at improving the competitiveness of human resources, labor and social sectors of economy, as well as improving the quality of social environment and living conditions of people.

Among the priorities of social policy, the Concept defines social protection of population (paragraph 8 of Part 3 of the Concept). It is planned to be implemented through development of non-governmental non-profit sector in provision of social services. It is planned to transform the majority of state and municipal social security institutions providing services to elderly and disabled people to non-profit organizations and to create a mechanism for attracting them on competitive basis to fulfill the state order for provision of social services. It is presumed that these organizations will carry out their activities, guided by the principle of transparency and based on competitive system of state support. The concept also marks development of practice of charity activities of citizens and organizations, as well as spreading of volunteering.

Striking illustration of state's intention to transfer implementation of social mission to private organizations of commercial and non-commercial nature is the Strategy for Development of Small and Medium-Sized Businesses in Russian Federation until 2030 [4]. It has great potential for development of small and medium-sized businesses in social sphere. At the same time, a number of measures are proposed aimed at increasing the share of small and medium-sized businesses in the field of social services. In particular, work on removing restrictions on the entry of new organizations into the social services market, creation and development of specialized infrastructure support organizations in constituent entities of Russian Federation, provision of subsidies for implementation of projects in the field of social entrepreneurship, measures to popularize such activities.

Consequently, they will need proper legal registration of relations arising between social entrepreneurs and their beneficiaries, as well as rethinking traditional notion of entrepreneurial activity that is well-established in civil law, since its classical characteristics do not reflect the essence of social entrepreneurship and even contradict it. In addition, the very definition of social entrepreneurship, its subjects and objects is not legal, and developed and established in the doctrine. All this predetermines relevance of the research topic chosen by the authors.

\section{Methods}

The methods used in the work: dialectics, analysis, synthesis, deduction, formal legal, comparative legal method.

Dialectics made it possible to push off from general theoretical ideas and find place for social entrepreneurship in general system of civil law (E.V. Bogdanov). Analysis and synthesis made it possible to identify subjects, objects and content of social-entrepreneurial 
relations, and also to give them an idea, to be classified as legal relations (Y.S. Grishina, A.V. Barkov).

The use of formal legal method in the study allowed us to describe, summarize and systematize the category of social entrepreneurship (Y.S. Grishina, O.A. Serova, Yu.G. Leskova, A.A. Burtseva). The comparative legal method made it possible to compare the concepts of "social entrepreneurship" and "social enterprise", to identify similarities and differences between them (Roger L. Martin, Sally Osberg, I. Khsanova G.V.).

Empirical basis of work. Social entrepreneurship combining primarily the potential of civil society, business and state is able to create the basis for sustainable development and renewal of city. Thus, the Center for Social Entrepreneurship and Social Innovations of the National Research University Higher School of Economics provides examples of transformation of urban areas by mobilizing resources from various stakeholders. In Peru, by mobilization of Small-business economic potential, slums of Lima have become cultural center. In India, local residents are attracted to the history of their area and joint restoration of cultural and architectural heritage [7]. This positive effect is achieved by public-private partnership.

At present, in countries with developed law and order, public-private partnership is recognized as part of a broader social phenomenon - social entrepreneurship, which is increasingly seen as an alternative to modern social policy that actually provides solution to various social problems in global crisis [8]. In Russian Federation, legal regulation of public-private partnerships as basis for transforming urban environment is laid down by adopting a law on public-private partnership, municipal-private partnership in Russian Federation and amending certain legislative acts of Russian Federation, [9]. In development of this law, the Government of Russian Federation adopted on January 1, 201614 regulatory legal acts, in particular, 10 resolutions of the Government of Russian Federation and 4 orders of the Ministry of Economic Development of Russia. The bylaws regulate procedures related to the preparation, consideration by the public side and evaluation of proposals for implementation of public-private partnership projects, as well as individual stages of tender procedures, subsequent control and monitoring of implementation of public-private partnership agreements. To date, at the federal level, the entire regulatory legal framework for implementation of public-private partnership projects has been formed. Within the framework of this type of social entrepreneurship, such projects are successfully implemented: in order to increase availability of sports and improve health of the population, indoor sports complex with artificial ice for 5,000 people (Ulyanovsk region), swimming pool in the city of Otradnoe, Kirovsky municipal district (Leningrad region) were created; in order to ensure availability of pre-school education, buildings of children's combines in Novosibirsk, kindergarten in the city of Perm have been reconstructed; in order to guarantee the rights of citizens to healthcare, separate building of the Center for Extracorporeal Hemocorrection and Clinical Transfusiology in Samara was built and put into operation. To ensure the right of citizens to additional education, the Republican Center for Children's and Youth Innovative Creativity was created in the city of Izhevsk (Udmurt Republic) [10]. These are just a few examples of improving urban environment by forces of public-private partnership, which is only one of the areas of social entrepreneurship.

In development of provisions of the Strategy for Development of Small and MediumSized Businesses in Russian Federation for the Period until 2030, the Ministry of Economic Development drafted a federal law "On Amendments to Certain Legislative Acts of Russian Federation (in terms of enshrining the concept of "social entrepreneurship")". The project identifies social entrepreneurship as a separate priority area of activity for small and medium-sized businesses, identifies special forms and types of support for social entrepreneurship, and provides for maintaining a register of social entrepreneurship entities. 
However, the bill is currently at the stage of public discussion. As rightly noted by A.V. Barkov and Ya.S. Grishin, significant remark to the draft law under discussion is that the Ministry of Economic Development of Russia does not include non-profit organizations as entities of social entrepreneurship, and therefore does not create holistic view of the phenomenon of social entrepreneurship.

The concept of long-term socio-economic development of Russian Federation for the period up to 2020 received logical continuation in the aspect of legal regulation of volunteering. In May 2019, the updated law "On charitable activities and charitable organizations", which will be called "On charitable activities and volunteering", will come into force. One of the main laws governing social entrepreneurship implemented by nonprofit organizations is the substantially updated Federal Law of Russian Federation "On Non-Profit Organizations", that regulates not only creation, types and implementation of control over the activities of non-profit organizations, but also establishes economic support measures for socially-oriented organizations, as well as recognition of socially-oriented organizations as a performer of socially useful services.

Review of research literature. Institute of social entrepreneurship is studied from different points of view, both economic and legal. Scientific works of foreign researchers reveal entrepreneurial activity as an economic function (A. Smith, W. Roscher, B. Hildebrand, A. Marshall, C. Menger, F. Vizer, J. Schumpeter). Russian scientists are studying economic characteristics of entrepreneurial activity (T.I. Zaslavskaya, Yu.N. Popov, V.A. Davydenko, I.V. Mikhalev). The status of an entrepreneur and specifics of his entrepreneurial activity are considered in works of V.I. Verkhovina, O. Inshakova, G.P. Lapin, N.I. Lomakin, A.Yu. Chepurenko.

It should be emphasized the monograph of E.V. Bogdanov "Contracts in the field of entrepreneurship." In this monograph, the author discovers regulation of economic relations by the state, including fulfillment of its social function, noting that: "The legislation regulating economic relations should be constantly improved in direction of its socialization and humanization. An indicator of sufficient development of this legislation should be not its so-called economic efficiency (economic efficiency of law), but social efficiency, how well legislation regulates economic relations in order to satisfy society in goods, services, works " [5]. It can be concluded that E.V. Bogdanov sees social side in every particular entrepreneurial relationship, thereby understanding social nature of entrepreneurship in the broadest sense, since any entrepreneurship is aimed at meeting the needs of society.

Comprehensive monographic research "Conceptual model of legal support for Russian social entrepreneurship" was carried out by Y.S. Grishina, who "developed recommendations for its practical implementation in form of author's concept of federal law "On state guarantees of social entrepreneurship development" and other system changes in legislation caused its legalization" [6].

Separate legal issues of social entrepreneurship are investigated by A.V. Barkov, A.A. Burtseva, O.A. Serova, A.V. Gurina, Yu.G. Leskov.

In the light of social changes, recognizing the importance of these studies for analyzing development of institution of social entrepreneurship, it should be noted that many aspects of the phenomenon under study need further discussion.

The purpose of the work is to search for meanings and mechanisms for understanding the legal category of social entrepreneurship, identifying its characteristics, characterizing subjects and designating main directions of development of legislation governing social business relations. The novelty of the research lies in formulation, justification and solution of tasks for determining the category of social entrepreneurship, identifying its characteristics, characterizing subjects and designating main directions of development of legislation governing social business relations. 


\section{Results}

Definition and features of social entrepreneurship

In Russian Federation, attempts are being made to consolidate legal definition of social entrepreneurship. According to the draft Federal Law "On Amendments to Certain Legislative Acts of Russian Federation" (in terms of enshrining the concept of "social entrepreneurship"), social entrepreneurship is the activity of small and medium-sized businesses, when one of the following conditions is observed:

a) small and medium-sized business ensures employment of disabled people, single parents with children up to 7 years, parents with many children, non-working pensioners, orphanage graduates under the age of 21 , persons released from prison and having conviction that has not been canceled or outstanding, provided that according to the results of previous calendar year, the average number of persons from any specified category of citizens among the employees of small and medium-sized business is at least 30 percent, and the share in the wage fund is at least 25 percent;

b) the subject carries on entrepreneurial activity aimed at improving living conditions of citizens and (or) expanding their ability to independently provide for their basic living needs, and (or) to support citizens who are in a difficult life situation, in accordance with the list of types of specified activity, approved by the Government of Russian Federation, provided that the share of income from such activities in previous calendar year is at least $70 \%$ in total entity revenue.

In general, in our opinion, existence of a law on social entrepreneurship in a particular state does not guarantee its high level of development and vice versa, since state of development of social entrepreneurship is raised by private individuals, civil society, and not by the state. For example, study conducted by the Thomson Reuters Foundation on the quality of basic conditions for social entrepreneurship in 2016 shows that Switzerland ranks 11th in the world, despite the fact that there is no legislation regulating social entrepreneurship in Switzerland, and according to the Bundesrat of Switzerland government determination and regulation will have negative impact on this young development of civil society, so it refrains from this."

However, in most EU member states there are specific legal provisions on social entrepreneurship, and efforts are being made to achieve common European legal status for social entrepreneurship.

The European Commission uses the term "social enterprise" to refer to following types of business in 4 areas:

1. Work integration - training and integration of people with disabilities and unemployed people;

2. Personal social services - health, well-being and medical care, vocational training, education, child care services, services for elderly, or assistance to disabled people;

3. Local development of disadvantaged areas - social enterprises in remote rural areas, schemes for development of neighborhoods in urban areas, assistance and cooperation in order to develop relations with third countries;

4. Other - including recycling, environmental protection, sports, art, culture or preservation of history, science, research and innovation, consumer protection and amateur sports.

Social enterprises combine social goals with entrepreneurial spirit. These organizations focus on achieving broader social, environmental, or community goals. The European Commission seeks to create favorable financial, administrative and legal environment for these enterprises so that they can work on a par with other types of enterprises in the same sector. 
Social entrepreneurship is not legal, but rather economic phenomenon. Its legal regulation is primarily related to particular importance of its implementation for society and desire of states to stimulate citizens and legal entities for implementation of social business.

The sign of direction of entrepreneurship as a whole towards systematic profit making goes against both ideas of social entrepreneurship and its real possibilities. Regarding the first statement, it should be noted that the goal of social entrepreneurship is precisely to achieve positive social effect, which can be achieved by implementation of activity, as well as deferred. For example, activity of creating a shelter for animals leads to an obvious decrease in the number of street animals, but activity of patriotic camp for children can be assessed only after many years, when children who took part in it grow up. Social entrepreneurs, according to Martin and Osberg, strive to create a new sustainable and more equitable "state of equilibrium" in society or in the target social group through direct influence.

Profit in social entrepreneurship is not its goal, since it is impossible to earn money on helping disabled people, retirees, large families, and animals. We can talk only about selfsufficiency, sustainability, and not in all the cases. It is necessary to agree with M.S. Volkova, who notes that social entrepreneurship creates new understanding of the category of "profit". In this case, profit is expressed in increment of social capital, bonds and public support. The main focus is on social welfare, while obtaining financial benefits is seen as a necessary condition for maintaining the viability of the organization.

This obvious fact underlies the state policy that is mainly aimed at financial and other support for social entrepreneurship. Legal policy in the field of ensuring financial sustainability of social entrepreneurship in Russia can be conditionally divided into two areas depending on subjects engaged in entrepreneurial activity.

Subjects of social entrepreneurship

In Europe, a single legal form for social enterprises does not exist. Many social enterprises operate in form of social cooperatives, some are registered as private companies, and many of them are non-profit organizations, such as public organizations, associations, voluntary organizations, charitable organizations or foundations.

The analysis of Russian legislation allows us to conclude that social entrepreneurs include, first, legal entities and individual entrepreneurs belonging to small and mediumsized businesses, and second, socially-oriented non-profit organizations that, by virtue of direct instructions of legislator, can engage in entrepreneurial activities in order to achieve the goals of creation (clause 2 of article 24).

The above draft law refers to the subjects of social entrepreneurship - entities engaged in activities related to social entrepreneurship, information about their belonging to social entrepreneurship entities is included in the unified register of small and medium-sized businesses.

Referring to the current legislation, it should be noted that according to Art. 30 of the Federal Law "On the contract system in the field of procurement of goods, works, services for state and municipal needs" customers are obliged to purchase from small businesses and socially oriented non-profit organizations in amount of not less than fifteen percent of the total annual purchases. At the end of the year, customer is obliged to compile a report on the volume of purchases from small businesses, socially oriented non-profit organizations, and before April 1 of the year following the reporting year, place such a report in united information system. In such a report, customer includes information on contracts concluded with small businesses, socially-oriented non-profit organizations, as well as information about failed determination of suppliers (contractors, performers) with participation of small businesses, socially-oriented non-profit organizations.

The above-stated law defined the second subject of social entrepreneurship, less deprived of legal regulation of relations with its participation - socially oriented non-profit 
organizations. Activity of this subject is regulated by the Federal Law "On Non-Profit Organizations." According to paragraph 2.1. Art. 2 of this law "socially oriented non-profit organizations are recognized non-profit organizations created in forms prescribed by current legislation (with the exception of state corporations, state companies, public associations that are political parties) and carrying out activities aimed at solving social problems, development of civil society in Russian Federation ".

In 2016, the President of Russian Federation identified priority areas of activity in provision of socially useful services, which in turn led to the emergence of new social entrepreneurship entity with special status; these are non-profit organizations that perform socially useful services. These organizations have priority in obtaining federal and regional support measures. According to statistics, a little more than 200 thousand non-profit organizations are registered in Russian Federation. The status of performer of public benefit services was obtained by 193 non-profit organizations over two years of existence of the mechanism for acquiring, which across the country does not look convincing. At the same time, the number of small and medium-sized businesses of commercial legal entities is 3.5 million. However, the interest of entrepreneurs in social entrepreneurship is low.

For example, in the city of Nizhnevartovsk, only $27 \%$ of entrepreneurs are interested in this type of activity in following areas: serving people with disabilities in various fields, education, social tourism, and medicine. Entrepreneurs who already have business in the field of social entrepreneurship, basically do not plan to expand current activities in this area. Only $16 \%$ are ready to expand their business through new activities, but only in the field of education.

In this regard, before making further changes to the legislation on small and mediumsized business, on social services for citizens, the choice of commercial legal entities for social entrepreneurship in terms of obtaining state support measures seems unjustified.

If we talk about directions of legal policy, at the State Council meeting, that took place on December 24, 2017, the President proposed to include all socially-oriented organizations in the list of performers of public benefit services that received support from the Presidential Grants Foundation. This proposal was motivated by fair and transparent system for evaluating activities of non-profit organizations. In our opinion, automatic assignment of the status of provider of socially useful services is not permissible, because it is not possible to guarantee the quality of services provided. It seems that the mechanism of assigning this status by relevant structural units of state bodies that assess professionalism of specialists, their qualification corresponds to a greater extent to the interests of beneficiaries, which is to receive quality social assistance. In addition, activities of organizations participating in competition for presidential grants do not always correspond to the priority areas of activity in provision of socially useful services, approved by Presidential Decree No. 398.

\section{Discussion}

The concept of "social entrepreneurship" is multifaceted; in the doctrine, it refers to entrepreneurial activity aimed at mitigating or solving social problems, and characterized by following main features: social impact, innovation, self-sufficiency and financial sustainability, entrepreneurial approach (G.V. Ikhsanova). Social entrepreneurship is also considered as an application of the way of thinking, processes, tools and technologies of ordinary business for the benefit of society and environment (I.A. Galkin). On the other hand, A.A. Burtseva notes the difference between the definitions of "income-generating activities" and "social entrepreneurship" as the main activities of socially-oriented organizations. In addition, social entrepreneurship is understood as both innovative (E. Vetrova, Y. S. Grishina) and as organizational activity (E. L. Zueva, S. Yu. Hovaev). 
The sign of direction of entrepreneurship as a whole towards systematic profit making goes against both the ideas of social entrepreneurship and its real possibilities. The lack of unified approach to understanding of social entrepreneurship as a special category leads to problems of law enforcement. The civil law doctrine proposes a number of ideas related to understanding the status of socially oriented non-profit organizations and justifying the need to distinguish them in civil law as an independent group of legal entities (A. Burtseva). Such an approach seems to be quite reasonable, as subjects involved in such a responsible activity as social entrepreneurship should guarantee quality of services provided. The results of this work can be further used in legal definition and identification of signs of social entrepreneurship as a legal phenomenon, legal forms of social entrepreneurship, public-private partnership and other aspects of social entrepreneurship.

\section{Conclusion}

In order to create developed socio-economic relations in Russia by building effective relations between social entrepreneurs and beneficiaries, it is necessary to clarify the content of the category of "social entrepreneurship".

Social entrepreneurship refers to both entrepreneurial and other activities aimed at solving social problems and stable socio-economic development of society. It would probably be worthwhile to abandon notion of entrepreneurship as applied to specified field of activity, since its main feature - making a profit - is excluded from its final definition.

The subjects of social entrepreneurship must be considered as a special category that requires proper legal registration. With definition of forms, goals and types of their activities, signs of such subjects separating from other subjects of civil law, requirements established by law, uniform reporting forms, etc., to build relationships in such a way that subjects of medium and small businesses have an interest in implementation of such activities. Without further changes in legislation on small and medium-sized business, on social services for citizens, the choice of commercial people for social entrepreneurship in terms of measures to obtain state support seems unjustified. Automatic assignment of the status of public service provider is not acceptable, because in this case it is not possible to guarantee the quality of services provided.

\section{References}

1. M.S. Volkova, Socio-economic phenomena and processes 10(9), 39-48 (2015)

2. A.A. Burtseva, Black holes in Russian legislation 5, 55-57 (2012)

3. Ya.S. Grishina, Bulletin of the Saratov State Law Academy 6(89), 117-122 (2012)

4. B. Mankovsky, The situation at the frontline of the socialist theory of Criminal law (Moscow, 1938)

5. A.V. Sumachev, Dispositive fundamentals in the German criminal law, Higher School Research (Tyumen, 2001)

6. A.V. Sumachev, Topical issues of protection of individuals, society and the state in the present day world: Reports of the Russian practice-oriented conference (Ufa, 2001)

7. A. Minnullina, MATEC Web of conference. 53, 08067 (2017)

8. A.V. Sumachev, Concerning dispositivity in the criminal law (Moscow, 2001)

9. B.V. Volzhenkin, Russian Criminal Law: Tradition, Modernity, Future, Materials of the conference (St. Petersburg, 2005)

10. G. Fletcher, A.V. Naumov, Basic Concepts of modern Criminal Law (Moscow, 1998) 